\title{
The benefits of incorporating basic sciences and translational research into a pharmacy school curriculum
}

\author{
Rachel R. Miller ${ }^{*}$ and Gregory S. Gorman ${ }^{2}$ \\ ${ }^{1}$ Department of Pharmacy, McWhorter School of Pharmacy, College of Health Sciences, Samford University, Birmingham, Alabama, USA \\ ${ }^{2}$ Department of Pharmacy, Director - Pharmaceutical Sciences Research Institute, McWhorter School of Pharmacy, Samford University, Birmingham, Alabama, USA
}

Research is the foundation that links the basic sciences to eventual clinical practice. Interpreting data from research is an ability that many healthcare workers need to have to provide safe, effective, and proficient patient care. For example, it is important for healthcare workers to be able to evaluate and understand data for new medications and how to apply it to their patients. Many academic institutions that train future healthcare workers incorporate research as a part of their curriculum [1]. This not only facilitates student learning, but also helps them to develop the critical thinking skills necessary to decipher research and to define new topics of research to translate into clinical practice.

The Accreditation Counsel for Pharmacy Education (ACPE), the national accrediting body for professional degree programs in pharmacy, dictates that schools teach both the foundational sciences such as biochemistry and pathophysiology as well as the pharmacotherapy courses based on evidence-based guidelines for patient care [2]. Additionally, ACPE supports pharmacy student involvement in research as a component of their education [2]. Students can participate in research through various opportunities offered by their respective schools of pharmacy. This can range from didactic or experiential electives to internships or senior projects. These opportunities add a different perspective to their clinical education beyond the requirements necessary for students to graduate.

Understanding and participating in the research process improves students' abilities to more effectively evaluate data and to be more confident in the clinical decisions they make regarding their patients' care [3]. Furthermore, it trains future pharmacists to practice with a perspective of continuous improvement in patient care outcomes, professionalism, and adds further input to the field of science [4]. In a study by Assemi, et al. (2015) at the University of California in San Francisco, about half of pharmacy students who participated in a senior research project at their university could circulate their research results in one or more of the following manners: poster, oral presentation, and publication [5]. Disseminating results is a critical step in the research process, and teaching other scientists and healthcare providers helps the students understand how their work applies to practice.

Research in a pharmacy school curriculum generally falls into three primary categories: educational, improvement of processes related to clinical practice, or basic pharmaceutical sciences research. The latter can be further broken down into two main areas based on their time-to-clinical application: long-term application studies and translational research. The long-term projects are more directed toward the foundational sciences. Specific examples of this include drug-drug or drug-herbal interactions, signal transduction research, and drug discovery and development evaluations. For instance, Kirby, Heard, and Wang (2013) discuss how various approaches to cystic fibrosis treatment can potentially improve clinical outcomes for those patients [6]. This study focused on the basic sciences component of ion channels, mutations, and protein misfolding commonly discussed in the biochemistry world [6]. Through this research, students evaluate concepts to improve cystic fibrosis treatment, thus linking the basic sciences to potential clinical application. Because these studies begin in an in vitro model and later progress to cellular and animal models before human testing can begin, it can take years until the results affect clinical practice [7].

Translational research is typically characterized by short-term work, resulting in a more immediate clinical impact. This type of research allows the students to see their laboratory data and monitor it as it translates into a clinical setting. Examples of translational experiments can include Y-site studies, drug stability testing, and determination of an extemporaneously compounded medication's shelf life. Cutshall and colleagues (2016) performed stability testing on the thrombolytic agent alteplase, which is indicated for acute ischemic stroke [8]. This study focused on the impact of various thawing conditions on residual enzyme activity [8]. As a result, healthcare workers are now able to use a more rapid method of thawing without loss in enzyme activity, thereby shortening the time to administration to the patient. Additionally, Malik, et al. (2016) performed drug stability testing on compounded bosentan monohydrate as an oral suspension used for pulmonary arterial hypertension [9]. Implementation of the results of this research resulted in an immediate cost savings by reducing waste of medicine and verified stability in a dosing vehicle that improved palatability to pediatric patients [9]. These are only a few examples of the types of research that students working with research faculty mentors can conduct, but many more options arise as clinical practice develops further.

These relationships with basic sciences faculty members, which are established early on in a pharmacy student's educational career, can be utilized to continuously improve patient care and outcomes. Including research as a part of clinical education is a proven and viable practice that helps to strengthen healthcare providers' clinical skills and establishes them as a more confident and critical resource on the healthcare team.

Correspondence to: Gregory S. Gorman, Ph.D, Director-Pharmaceutical Sciences Research Institute, Vice-Chair PSAS, McWhorter School of Pharmacy, Samford University, USA; Tel: +1 205-726-4452; E-mail: ggorman@samford.edu

Received: October 14, 2016; Accepted: October 27, 2016; Published: October 29,2016 


\section{References}

1. Kao DJ, Hudmon KS, Corelli RL (2011) Evaluation of a required senior research project in a doctor of pharmacy curriculum. Am J Pharm Educ 75: 5. [Crossref]

2. Accreditation Council for Pharmacy Education. Accreditation Standards and Key Elements for the Professional Program in Pharmacy Leading to the Doctor of Pharmacy Degree ("Standards 2016"). Approved January 25, 2015. Released February 2, 2015.

3. Ramsauer VP (2011) An elective course to engage pharmacy students in research activities. Am J Pharm Educ 75: 138. [Crossref]

4. American Society of Health-System Pharmacists Commission on Credentialing. Guidance Document for the ASHP Accreditation Standard for Postgraduate Year One (PGY1) Pharmacy Residency Programs. Updated September 2016.
5. Assemi M, Ibarra F, Mallios R, Corelli RL (2015) Scholarly contributions of required senior research projects in a doctor of pharmacy curriculum. Am J Pharm Educ 79: 23.

6. Kirby EF, Heard AS, Wang XR (2013) Enhancing the Potency of F508del Correction A Multi-Layer Combinational Approach to Drug Discovery for Cystic Fibrosis. $J$ Pharmacol Clin Toxicol 1: 1007. [Crossref]

7. U.S. Food and Drug Administration. Step 2: preclinical research. http://www.fda. gov/ForPatients/Approvals/Drugs/ucm405658.htm. Updated 06/24/2015. Accessed $11 / 04 / 2016$

8. Cutshall BT, Gorman GS, Freeman MK, Kyle JA (2016) Enzymatic stability of alteplase solution for injection: effect of various methods of thawing frozen solutions. Hosp Pharm 51: 246-251

9. Malik A, Gorman G, Coward L, Arnold JJ (2016) Stability of an Extemporaneously Compounded Oral Suspension of Bosentan. Hosp Pharm 51: 389-395. [crossref]

Copyright: (C2016 Miller RR. This is an open-access article distributed under the terms of the Creative Commons Attribution License, which permits unrestricted use, distribution, and reproduction in any medium, provided the original author and source are credited. 